\title{
LIPOLYTIC ACTIVITY OF SOME DERMATOPHYTES. II. ISOLATION AND CHARACTERISATION OF THE LIPASE OF EPIDERMOPHYTON FLOCCOSUM
}

\author{
L. Hellgren AND J. VinCENT \\ Department of Dermatology, Faculty of Medicine, University of Trondheim, 7000 Trondheim, \\ Norway
}

Summary. The physicochemical properties, stability and localisation of lipase from the anthropophilic dermatophyte Epidermophyton floccosum have been investigated. The lipase was best secreted by older cultures at an optimum $p \mathrm{H}$ of 6.5-7 in the temperature range $40-45^{\circ} \mathrm{C}$. Neither the skin-surface lipids nor the body temperature of man significantly affected the activity of the lipase.

\section{INTRODUCTION}

The distribution of dermatophyte lipids and their importance in the pathogenesis of dermatophytosis has been recently reviewed by Vincent (1978). The lipolytic activity of Epidermophyton floccosum, Microsporum canis, Trichophyton rubrum and T. mentagrophytes has also been screened as a function of different substrates (Hellgren and Vincent, 1980).

Lipolytic enzymes are important for the development of dermatomycosis because dermatophytes, in their first phase of growth, depend solely on their ability to split surface lipids to reach the stratum corneum. However, there is little information on the lipolytic systems and their physiological functions in dermatophytes. It is therefore important that these fungal lipases be more thoroughly characterised. In this study we investigated the physicochemical properties, stability and localisation of lipase isolated from an anthropophilic dermatophyte, Epidermophyton floccosum.

\section{MATERIALS AND METHODS}

Growth conditions. Freshly isolated strains of E. floccosum were cultured on the liquid medium of Blain, Patterson and Shaw (1978). For enzyme recovery the substrate was inoculated with $0.1 \mathrm{ml}$ of standard mycelial suspension (Vincent, 1972) of the dermatophyte and incubated for 1 month at $30^{\circ} \mathrm{C}$. Each batch was run in a series of replicates with at least seven separate cultures. The mycelial mass was removed by combined filtration and centrifugation of the substrate and the culture filtrates were directly used for measurements of lipolytic activity.

Lipase assay. Activity of the lipase was determined titrimetrically. The reaction mixture, composed of $5 \mathrm{ml}$ of culture filtrate, $4.5 \mathrm{ml}$ of lipase buffer (Borgström and Erlanson, 1973) and $0.5 \mathrm{ml}$ of tributyrine, was incubated at $35^{\circ} \mathrm{C}$ for $3 \mathrm{~h}$. Immediately after incubation, $20 \mathrm{ml}$ of acetone:ethanol mixture $(1: 1)$ was added and the liberated fatty acids titrated with $0.05 \mathrm{~N}$ $\mathrm{NaOH}$. In the same manner, enzyme temperature and $p \mathrm{H}$ optima were established by adjustment of the assay mixture to different $p \mathrm{H}$ or by incubation at different temperatures. To confirm the velocity of some reactions, the hydrolysis products were extracted and analysed by thin-layer chromatography.

Received 29 Oct. 1980; accepted 24 Nov. 1980.

Correspondence and requests for reprints to Dr J. Vincent. 


\section{RESULTS}

The lipolytic activity of $E$. floccosum was observed during the whole growth period. The excretion rate increased continuously with age of the culture (fig. 1). This was confirmed by chromatographic identification of hydrolysis products. The optimum $p \mathrm{H}$ for E. floccosum lipase (fig. 2) lay in the range 6.5-7.0, and greater changes in $p \mathrm{H}$ did not abolish enzyme activity; e.g., at $p \mathrm{H} 5.5$ or 9.0 up to $\sim 50 \%$ of the activity could be recorded. The intensity of the substrate degradation increased with rising temperature up to $40-45^{\circ} \mathrm{C}$ and then rapidly fell. However, for routine measurements a temperature of $35^{\circ} \mathrm{C}$ is recommended (fig. 3).

The stability of $E$. floccosum lipase was also evaluated. We concluded that this lipase is a relatively slowly acting enzyme. Moreover, when the enzyme was incubated at $50-70^{\circ} \mathrm{C}$ its activity rapidly decreased. Incubation for $15-30 \mathrm{~min}$ at $60^{\circ} \mathrm{C}$ resulted in a drastic decline of the lipolytic activity. This thermosensitivity of the lipase indicates a protein character.

Finally, in our experimental conditions, we failed to establish whether or not there was also a passive liberation of endoenzymes, especially in the late stationary and autolytic growth phase.

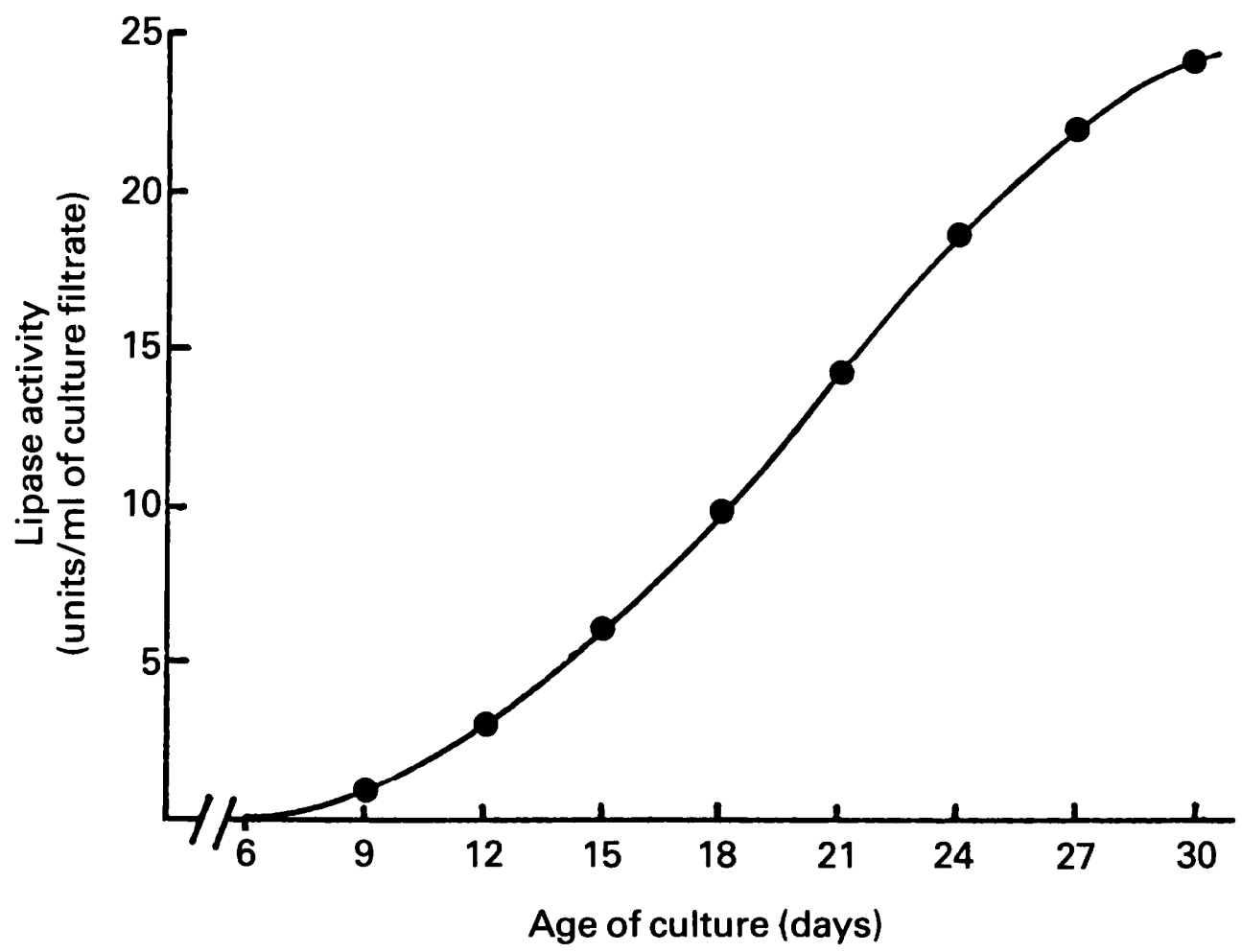

FIG. 1.-Relationship between the growth of E. floccosum and lipase activity (expressed as titratable fatty acids liberated over a 3-h period). The experimental conditions are described in the text.

\section{Discussion}

Even if $E$. floccosum generates lipase during its whole growth period, it is in the older cultures that lipase production predominates. Dermatophyte lipases are not labile, and this facilitates their action in the skin before the fungus reaches the keratin-rich layers of the epidermis. It is 


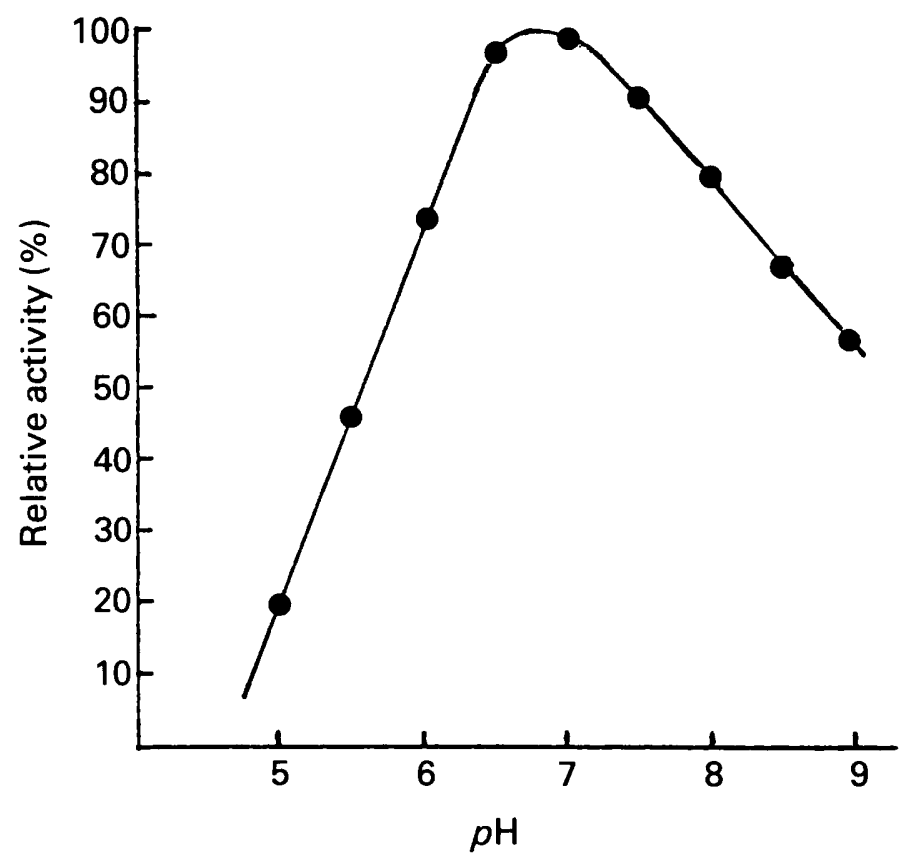

FIG. 2.-Effect of $p \mathrm{H}$ on lipase activity in culture filtrate of E. floccosum.

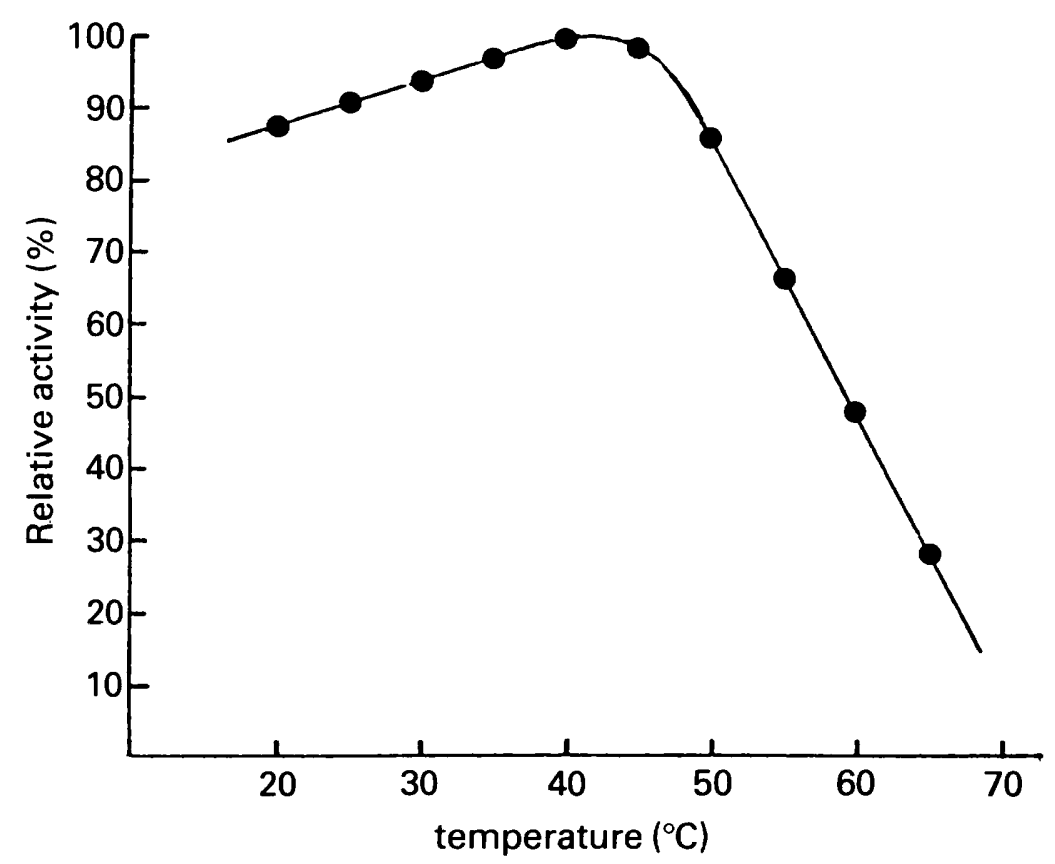

FIG. 3.-Effect of temperature on lipase activity in culture filtrate from E. floccosum 
noteworthy that, despite the fact that the optimum $p \mathrm{H}$ of $E$. floccosum lipase was found close to $p \mathrm{H} 7$, the acid mantle of the skin seems only partially to affect fungal enzymatic activity. Fatty-acid content in the skin surface lipids never reaches levels that could inhibit the growth of dermatophytes and the extent of lipolysis seems thus to be controlled by a feedback mechanism. This is probably due to the active alkalinisation of the substrate by dermatophytes (Paveia, 1975) which in turn leads to the skin buffer capacity being overcome. Moreover, the keratinous structures swell in alkaline milieu, and this facilitates an easier penetration of the dermatophytes into the stratum corneum. Zucker (1964) reported a constitutional higher $p \mathrm{H}$ value associated with a decreased buffering capacity of the skin in patients with dermatomycosis compared with healthy controls; and this may suggest a predisposition to the disease in certain individuals.

\section{REFERENCES}

Blain, J. A., Patterson, J. D. E. and Shaw, C. E. L. 1978. The nature of mycelial lipolytic enzymes in filamentous fungi. F.E.M.S. Microbiol. Lett., 3, 85.

Borgström, B. and Erlanson, C. 1973. Pancreatic lipase and colipase. Interactions and effects of bile salts and other detergents. Eur. J. Biochem., 37, 60 .

HellgREN, L. AND VinCENT, J. 1980. Lipolytic activity of some dermatophytes. J. med. Microbiol., 13, 155.

PaveIA, M. H. 1975. Culture medium alkalinization by dermatophytes. The influence of time and temperature of incubation. Mycopathologia, 55, 35 .

VINCENT, J. 1972. Mycelial suspensions prepared ultrasonically. Experientia, 28, 722.

VInCENT, J. 1978. Dermatophyte lipids. Progr. chem. Fats. Lipids, 16, 171.

ZUCKER, G. 1964. Untersuchungen über Zusammenhänge zwischen der Infektionsbereitschaft der Haut gegenüber Dermatomykosen und dem $\mathrm{pH}$, dem Alkalineutralisationsvermögen, dem Oberflächenfett sowie der Temperatur der Haut, Ph.D thesis, Humboldt Universität, Berlin. 